\title{
ÉTICA E POLÍTICA EM MICHEL FOUCAULT
}

\author{
Cesar Candiotto ${ }^{1}$
}

RESUMO: Pretende-se analisar como, no pensamento de Michel Foucault, a investigação em torno da ética do cuidado de si pode ser lida como desdobramento da ideia de governamentalidade, problematizada a partir de 1978; procura-se indicar, ainda, que essa ética do cuidado de si é a condição do governo político dos outros, na leitura da tradição socrática, o que possibilita uma revisitação da política. Mas, desde a avaliação que Foucault faz da figura de Sócrates em relação à política ateniense até seu diagnóstico da política contemporânea, essa revisitação tem sido conflitante, pelo menos quando se trata da constatação da maneira como as instituições políticas cuidam dos cidadãos. Esse conflito beira ao paradoxo, posto que, ao mesmo tempo em que a biopolítica afirma uma política da vida, no sentido de proporcionar seu cuidado, preservação, longevidade, observa-se também a atuação de uma política sobre a vida, enquanto vida controlada e submetida ao biopoder. Essa discrepância entre dispositivos discursivos e práticas efetivas demonstra uma ausência do cuidado da verdade, entendido aqui como coerência entre o que se diz e o que se faz. Enquanto desdobramento do cuidado de si, o cuidado da verdade pode ser interpretado como uma chave de leitura fundamental para o diagnóstico dos riscos e perigos que ameaçam recorrentemente a vida humana.

PALAVRAS-CHAVE: Ética. Política. Cuidado de si. Cuidado da Verdade. Genealogia.

${ }^{1}$ Professor do Programa de Pós-Graduação em Filosofia da PUCPR. Bolsista de Produtividade em Pesquisa do CNPq - Nível 2. E-mail: ccandiotto@gmail.com 


\section{Introdução}

Durante os anos 1970, a investigação de Foucault indicava que o sujeito é constituído com base em condições políticas, tais como as práticas judiciárias. No entanto, isso não quer dizer que as estruturas políticas se impunham do exterior a um sujeito pré-constituído; inversamente, ao objetiválo como isso ou aquilo, o sujeito era mero efeito das relações de poder presentes nas diversas práticas sociais e políticas.

A avaliação crítica da trajetória de Foucault, em meados dos anos 1970, após a publicação de Histoire de la séxualité, v. I (1976), era a de que ele chegara a um impasse, no sentido de que seria impossível ir além do próprio poder, a não ser que houvesse uma mudança de rumo.

A introdução do conceito de cuidado de si, nos dois últimos volumes de Histoire de la séxualité (ambos de 1984), em vez de ter sido apresentada como uma alternativa àquele impasse, parecia mais indicar uma linha de fuga malfadada, uma idealização da cultura clássica muitas vezes espiritualizada e apaziguada em comparação à constituição política do sujeito moderno, enfatizada na sua analítica do poder. ${ }^{2}$ Provavelmente, porque as interpretações que geralmente têm sido atribuídas ao cuidado de si parecem não se conformar com a vida militante do pensador, com suas intervenções a respeito da política de sua época, sobretudo nas declarações e entrevistas desconcertantes sobre o socialismo francês dos anos oitenta, sobre os direitos humanos, sobre a esquerda francesa, mas também sobre o liberalismo clássico e o neoliberalismo contemporâneo. Além disso, esse desconforto é acentuado porque, nas ciências humanas, sociais e biomédicas, o cuidado de si é associado à terapia, normalmente referido ao cuidado do corpo e da saúde psíquica; já na área da filosofia, ele tem sido abordado em comparação ao conhecimento de si e seu recorrente contraste entre o antigo imperativo socrático e o "momento cartesiano". ${ }^{3}$

\footnotetext{
${ }^{2}$ Para Foucault, há diferenças notáveis entre uma teoria do poder e uma analítica do poder. A primeira, comumente desenvolvida pelas teorias jurídicas e pela filosofia política clássica, aborda o poder como se fosse uma coisa, substância cuja essência pode ser descrita em sua estrutura e funcionamento. Já a segunda negligencia o poder como objeto a ser descrito ou essência a ser representada. O poder é analisado em seus efeitos, como a confluência de estratégias plurais, como relação e exercício. "O poder não é uma instituição, não é uma estrutura, não é uma certa potência da qual alguns seriam dotados: é o nome que atribuímos para uma situação estratégica complexa numa sociedade dada" (FOUCAULT, 1976, p. 123).
}

${ }^{3}$ Foucault denomina "momento cartesiano" não exclusivamente a filosofia de Descartes. Senão, vejamos: "[...] se fizermos agora um salto de muitos séculos, podemos dizer que 
Pensamos que essas interpretações da trajetória do pensamento foucaultiano, incluídas aí aquelas que giram em torno do conceito de "cuidado de si", ainda que consistentes até a primeira metade dos anos 1990 (posto que, até então, tinha-se somente uma análise esparsa e insuficiente do conjunto de textos publicados em 1994, intitulados Dits et écrits, 4v. e os cursos sequer tinham começado a ser publicados), apresentamse atualmente insuficientes diante da publicação dos últimos cursos no Collège de France, a começar por Sécurité, territoire, population (2004). A partir das contribuições proporcionadas por essa bibliografia mais recente, almeja-se demonstrar neste estudo, que as possibilidades de análise do cuidado de si na investigação de Foucault podem ter um alcance que transcende tais interpretações e, ao mesmo tempo, propiciam diagnósticos instigantes para a sociedade atual.

Inicialmente, aponta-se como, na trajetória filosófica foucaultiana, o cuidado de si surge em função do desdobramento da ideia de governamentalidade, problematizada desde 1978. A partir desse momento, indica-se que o cuidado ético de si é a condição do governo político dos outros, na leitura da tradição socrática, uma vez que ele proporciona uma revisitação inusitada da política. Mas, justamente, essa revisitação da política pela ética do cuidado de si é que tem sido problemática, tendo em vista a avaliação que Foucault faz da figura de Sócrates em relação à política ateniense até seu diagnóstico da época contemporânea, pelo menos quando se trata da constatação da maneira como as instituições políticas "cuidam" dos cidadãos. Diante dessa leitura é que pensamos ser possível, num terceiro momento, indicar articulações promissoras entre ética e política, no pensamento contemporâneo. Sem descartar outras possibilidades, o cuidado da verdade, como desdobramento do cuidado de si, será apresentado como uma das chaves interpretativas significativas para tratar de tal articulação, uma vez que ele nuança com justeza os limites da ambígua ideia de "cuidado da vida" propalado pela política atual, no sentido de administração, de gestão e de preocupação com a vida.

entramos na idade moderna (quero dizer, a história da verdade entrou no seu período moderno) no dia em que admitimos que o que dá acesso à verdade, as condições segundo as quais o sujeito pode ter acesso à verdade, é o conhecimento e tão-somente o conhecimento. É aí que, parece-me o que chamei de 'momento cartesiano' encontra seu lugar e sentido, sem que isso signifique que é de Descartes que se trata, que foi exatamente ele o inventor, o primeiro a realizar tudo isto" (FOUCAULT, 2001, p. 19). 


\section{Cuidado de si e Governamentalidade}

A primeira parte da exposição desenvolve a hipótese de que a expressão "cuidado de si" surge no vocabulário de Foucault como desdobramento da ideia de governamentalidade.

Em Les anormaux (1975/1999), Foucault se refere a uma daquelas dimensões das então chamadas "artes de governar" dos outros. Assim, ele já menciona o "governo das crianças", o "governo dos loucos", o "governo dos pobres" e o "governo dos operários" (FOUCAULT, 1999, p. 45). Mas, nesse caso, o surgimento da preocupação com o domínio do governo é entendido na perspectiva dos mecanismos de normalização da sociedade, que se estendem da Reforma e Contra-Reforma do século XVI e seguem com as instituições disciplinares a partir do século XVII.

Em Sécurité, territoire, population (1978/2004), o neologismo "governamentalidade" ${ }^{5}$ se torna o pano de fundo do domínio do governo dos outros, até o momento somente referido. Além disso, a ideia de governamentalidade possibilita, ainda que não de maneira totalmente explícita, a introdução de outro domínio, que é o do governo de si mesmo. Doravante, a arte de conduzir os outros e a maneira pela qual conduzimos a nós mesmos (FOUCAULT, 2004, p. 197) são os dois domínios constitutivos da governamentalidade. ${ }^{6}$ Foucault sugere a aplicação da governamentalidade no significado prevalentemente moral, para diferenciá-

\footnotetext{
${ }^{4} \mathrm{Um}$ excelente estudo sobre as artes de governar pode ser encontrado em Senellart, 1995

${ }^{5}$ Do original gouvernamentalité, inexistente nos principais dicionários de língua francesa. Em português, ora a palavra é traduzida por governabilidade, ora por governamentalidade, o que pode resultar em confusões conceituais. Veiga-Neto (2002, p. 20-33) apresenta diversos argumentos em prol do uso de governamentalidade e não governabilidade. Um deles é o que segue: enquanto governabilidade "denota a qualidade daquele ou daquilo que se pode governar ou que se deixa governar, que é dócil, que é obediente", governamentalidade seria mais adequado ao emprego feito por Foucault de gouvernamentalité, como a "qualidade segundo a qual o Estado foi se tornando governamental". Por referir-se mais às questões governamentais vinculadas ao surgimento do Estado moderno do que propriamente a algo ou alguém que pode ser governado ou dirigido, ou a algo ou alguém que é dócil e obediente, prefere-se o conceito governamentalidade. Além da razão aduzida, vale ressaltar que, na tradução inglesa do termo, não foi utilizada a palavra já dicionarizada governableness, mas o neologismo governmentality. Finalmente, em virtude de sua minuciosa elaboração e sua significativa contribuição, o conceito governamentalidade não carregaria ainda mais a língua portuguesa, mas contribuiria para seu enriquecimento.

${ }^{6}$ Dentre os diversos estudos sobre a governamentalidade problematizada por Foucault, podem ser destacados: LEMKE, 2002; GORDON,1991; KERR, 1999; SENELLART, 2003 e
} 
lo de sua acepção material (como gestão do deslocamento de uma população em busca de subsistência) e de sua conotação administrativa mais recente (no sentido de governo ou administração estatal).

A ênfase no governo de si mesmo em face do governo dos outros é que propiciou a conceitualização do cuidado de si, do modo como pretendemos interpretá-lo. Diante das várias designações oferecidas no curso L'herméneutique du sujet (2001, p. 6-20), no dia 6 de janeiro de 1982, uma delas é particularmente fundamental para nosso recorte teórico. Foucault sustenta que o cuidado de si é um "princípio de agitação, um princípio de movimento, um princípio de inquietude permanente" (FOUCAULT, 2001, p. 9). Essa designação também auxilia a compreender como o conceito está distante de um apelo exclusivamente individualista; antes, ele invoca a nãopassividade, o desprendimento contínuo de nosso eu conformista.

Essa atitude de separação do eu se mostra fundamental quando se trata da proposição de resistências em face de um governo qualquer. Como "princípio de inquietação permanente", o cuidado de si tem uma aplicação claramente política. Na governamentalidade, o ato de conduzir os outros não exige a atitude de passividade ou a anulação da liberdade daquele que é conduzido. O outro da condução deverá sempre ser considerado um sujeito de ações, o que implica a possibilidade de "contracondutas" ; estas constituem um dos domínios da governamentalidade que é a do governo de si mesmo, do direito dos governados de limitar os excessos dos diversos modelos de governança, de ordem doméstica, política, pedagógica, espiritual, médica.

Governar é agir sobre si mesmo, em vistas de se posicionar criticamente diante de quaisquer ações de condução. Inexistem relações de governo que não sejam aquelas exercidas sobre sujeitos livres ${ }^{8}$, que dispõem de um campo plural

\footnotetext{
${ }^{7}$ Em Surveiller et punir (1975), Histoire de la séxualité, I: La volonté de savoir (1976), Il fault défendre la société (1976), Foucault estabelecia a imanência entre relações de poder e resistências. Contudo, diante da concepção microfísica de tais relações, a partir das quais se tornava difícil identificar onde estava o poder e quem o detinha, criticava-se Foucault a respeito da concepção também capilar das resistências. Afinal, resistir a quem e a que, se o poder não é identificável, se ele não emana de um único lugar? A partir de 1978, por ocasião da problematização da governamentalidade, o poder continua a ser pensado em termos relacionais, ou seja, de uma analítica do poder. No entanto, já é possível identificar tais relações de maneira menos disseminada, ora envolvendo o governo da consciência das almas, ora o governo doméstico, o governo político e o governo pedagógico. Foucault passa, por conseguinte, a designar de "contracondutas" uma maneira de governar a si mesmo que se impõe diante daqueles diferentes modos de governar.

${ }^{8}$ Normalmente, a liberdade está vinculada a uma ontologia da subjetividade, como um pressuposto jurídico e filosófico inerente ao sujeito. Foucault jamais chega a tematizar a liberdade, e concordaria que ela é um objeto cujo fundamento é o sujeito moral. Como
} 
de possibilidades e alternativas. Essas alternativas se estendem, desde a aceitação de uma determinada condução até a constituição de contracondutas ao modo como ela é exercida. As contracondutas são elevadas a novo ponto de partida, diante das diferentes relações de governo; elas designam um cuidado político de si, porque o sujeito é constituído como tal em virtude da relação política do governo de si mesmo em face do governo dos outros.

Na sua dimensão política, o cuidado de si está situado na relação de forças entre o eu e os outros; na efetivação das contracondutas, no sentido de não ser governado de uma determinada maneira, a partir de certos métodos, e em nome de agentes determinados. Na linguagem de Foucault, há aqui uma espécie de "jogos estratégicos entre liberdades - jogos estratégicos que fazem que uns tentem determinar a conduta dos outros, aos quais estes outros respondem tentando não deixar determinar sua conduta ou tentando determinar, em retorno, a conduta dos outros" (FOUCAULT, 1994, p. 728). Como é possível imaginar, o cuidado político de si perpassa as relações interindividuais, tais como as relações de gênero, o mundo laboral, educacional e familiar e o próprio governo político.

\section{A Ética do Cuidado de Si}

Na sua dimensão ética, o cuidado de si implica outro jogo de forças, do eu para consigo. Trata-se de um embate no próprio indivíduo, na distância entre a condescendência aos seus desejos e a sua limitação pelas práticas de liberdade. Estamos no centro daquele âmbito da maneira pela qual é necessário conduzir-se em vistas de uma "relação consigo" ou de uma ética, como quer Foucault (FOUCAULT, 1984, p. 40).

O difícil trabalho ético consiste em reconhecer, de um lado, a recorrência dos desejos e das ambições pessoais; de outro, a possibilidade de contracondutas constituídas pelas práticas de liberdade que limitam tais desejos e ambições. O cuidado de si evoca a luta agonística e incessante, o embate travado no próprio indivíduo, o inconformismo diante das tendências egoístas e hedonistas.

afirma Larrosa (2000, p. 334): "E assim, frente à liberdade bem fundada de um sujeito soberano que sabe o que quer e que projeta sua realização no futuro, talvez possamos dizer que a liberdade só aparece quando o próprio sujeito se percebe como não-fundado, como carente de qualquer razão ou de qualquer princípio que pudesse dar conta dele. E talvez a liberdade não seja outra coisa senão aquilo que acontece nessa experiência, na experiência dessa falta de fundamento, de princípio ou de razão, na experiência de um ser que não pode dar nada por fundado, nem seu saber, nem seu poder, nem sua vontade, nem sequer a si mesmo e que, justamente por isso, salta para fora de tudo o que o mantinha seguro e assegurado, dono de si, idêntico a si mesmo". 
O primeiro domínio de aplicação dessa luta agonística é o do autoconhecimento. Em Le sujet et le pouvoir, depois de mostrar que "estar sujeito a" significa estar sujeito à dependência de outrem e ao seu controle, Foucault ressalta que a expressão também significa estar sujeito ao autoconhecimento que temos de nós mesmos, uma espécie de imagem distorcida de quem somos. Isso ocorre porque, geralmente, o conhecimento de nós mesmos está demasiadamente atrelado à identidade que as chamadas ciências do homem nos levam a aceitar, a torná-la quase algo natural. As verdades associadas a essa identidade normalmente trazem embutidos efeitos de poder em função dos quais somos classificados como normais ou anormais, por exemplo. Quando Foucault enfatiza que é preciso desprender-se do eu, é desse eu mimético que subjetivamos de maneira sujeitada a que ele se refere. Paradoxalmente, o cuidado de si, como princípio de inquietude, acarreta um descuidar-se do eu normalizado. Esse conhecimento verdadeiro do eu legitimado pelas ciências do homem é basilar e, às vezes, considerado exclusivo na função de forjar identidades. Privilegiar o cuidado com o saber, e não exatamente aquele conhecimento do eu, é fundamental para entender o último Foucault. "De que valeria a obstinação do saber se ele assegurasse apenas a aquisição dos conhecimentos e não, de certa maneira, e tanto quanto possível, o descaminho daquele que conhece?" (FOUCAULT, 1984, p. 15).

Cuidar de si é esse movimento que nos impulsiona a deixar de ser nós mesmos, no sentido de tomar distância de nossa identidade préconstituída. Foucault também chamou esse movimento de desassujeitamento.

A via escolhida consiste no estabelecimento de uma relação diferenciada entre conhecimento de si e cuidado de si. $^{9}$ O princípio do cuidado exige uma apropriação diferente do conhecimento. Só será útil aquele conhecimento que ajude na modificação de nossa maneira de ser. Decididamente, Foucault se voltará para o estoicismo romano e para o epicurismo, para abordar essa problemática. Provavelmente, não para neles buscar todas as respostas plausíveis para os interrogantes da identificação moderna. Ora, cada época tem suas perguntas, suas respostas, seus conceitos. O percurso pelo canteiro histórico do pensamento helenístico e imperial somente quer mostrar que, na cultura ocidental, nem sempre foi a busca de uma identidade da natureza humana ou a verdade escondida nos segredos da consciência a chave de uma história da subjetividade. Pelo contrário. Pensadores como Epicuro se preocupavam especialmente com aqueles conhecimentos úteis para que o ser humano soubesse se defender,

${ }^{9}$ A respeito dessa relação, podem ser destacados os seguintes estudos: GROS, $2001 \mathrm{e}$ 2003; MUCHAIL, 2007. 
diante dos acontecimentos inesperados da existência. Saber que há poucas situações em relação às quais o ser humano pode amedrontar-se, que nada há de se temer quanto aos deuses, que a morte produz mal algum, que é necessário encontrar o caminho da virtude e que o indivíduo nasce para a comunidade, são conhecimentos que afastam o temor, induzem à transformação do eu e aperfeiçoam sua relação com os outros.

Esses conhecimentos implicam uma relação diferente com o tempo, como é possível perceber. Se for verdade que sempre devemos estar preparados, por meio de uma espécie de praemeditatio malorum, para as vicissitudes futuras de uma doença incurável, da perda de um ente querido e, principalmente, para a iminência da morte, é certo que tal preparação exige uma atenção no presente. A atenção ao instante presente ajuda o indivíduo a desviar-se das paixões provocadas pelo saudosismo inútil do passado ou da ilusão inconsequente a respeito do futuro.

Nunca é demais recordar algumas sentenças de Epicuro a esse respeito: "Recordemos que o futuro não é nosso nem de todo não nosso, para não termos de esperá-lo como se estivesse para chegar, nem nos desesperarmos como se em absoluto não estivesse para vir." Ou esta outra: "A vida do insensato é ingrata, encontra-se em constante agitação e está sempre dirigida para o futuro". Epicuro também poderia nos levar a pensar por que a ansiedade consumista tem a ver justamente com a falta de atenção ao momento presente. Diz Epicuro: "Não deves corromper o bem presente com o desejo daquilo que não tens; antes, deves considerar também que aquilo que agora possuis se encontrava no número dos teus desejos" (EPICURO, 1973, p. 26-27). Nesse caso, é preciso que o indivíduo se concentre no momento presente. Somente o presente depende da ação livre, apenas nas ações presentes ele está se constituindo como sujeito ético. Trata-se, pois, de sujeito em ação, em processo permanente de cuidado de si; ele só se constitui em sujeito, quando age e enquanto age sobre si mesmo.

\section{O Cuidado de Si Como Condição do Governo dos Outros}

A hipótese de Foucault é a de que, entre gregos e romanos, o cuidado ético de si é indissociável do cuidado político dos outros. Isso se a relação com os outros for entendida como uma maneira de exercitar nosso ser político (o enfrentamento entre indivíduos que empreendem ações livres); e, de igual maneira, a ética for concebida como o âmbito das relações consigo (o embate que ocorre, no próprio indivíduo, entre os desejos desmedidos e os limites do seu agir livremente). 
Se anteriormente se afirmou que o cuidado de si era um desdobramento da governamentalidade, agora a hipótese é de que, nos últimos ditos e escritos, Foucault faz dele a condição fundamental para o governo dos outros..$^{10}$ Daí ser o epimeleia heautou (cuidado de si) um dos fios condutores para entender a revisitação da própria política (um dos pontos de aplicação, mas não único, do governo dos outros), a partir da problematização da ética.

Para permanecer fiel ao recorte teórico deste artigo, não será problematizada a elasticidade de domínios do governo dos outros, na Grécia clássica, que inclui o governo da mulher, dos filhos e da casa. ${ }^{11}$ A atenção será dirigida para a relação entre o governo político dos outros e o governo de si mesmo. Para isso, primeiro será feita uma breve referência às aulas iniciais de 1982, enunciadas por Foucault no Collège de France, em torno do Primeiro Alcibíades de Platão. Posteriormente, serão analisados alguns aspectos do diálogo A Defesa de Sócrates, abordados por Foucault, no curso Le gouvernement de soi et des autres, v. I, de 1983.

O Primeiro Alcibíades, um dos diálogos de juventude de Platão, tem como pano de fundo a relação entre o governo político e o governo de si mesmo. Não é o caso de entrar no mérito desse personagem, Alcibíades, já abordado diligentemente em outros estudos. A título de contextualização, somente enfatizamos que Alcibíades pretende desfrutar do privilégio político do governo dos outros, especificamente, o governo administrativo de Atenas. Ele avalia que seu status privilegiado, derivado da ascendência aristocrática, é suficiente para o bom êxito de um futuro governo. No entanto, ele não se encontra preparado para o exercício da arte de governar, na seara política. Ignora a tékhne necessária daquilo que deveria saber; pretende governar a cidade, mas não sabe como fazê-lo e qual é o fim da atividade política. Somente nesse momento é que Sócrates decide abordá-lo; e o escopo dessa

\footnotetext{
${ }^{10}$ Essa hipótese é sustentada por Pradeau, 2003, p. 35-52.

${ }^{11}$ Para o homem livre grego, quer dizer, aquele que exerce algum tipo de atividade pública ou governo da cidade, era importante incluir no seu "bem conduzir-se" a justa maneira de governar sua mulher, seus filhos e seu lar. Essa justa maneira pressupunha um autodomínio (enkrateia) no uso dos prazeres (Khresis aphrodisia) como o poder exercido sobre si mediante o poder sobre os outros (FOUCAULT, 1984). Foucault, inspirando-se na Política, de Aristóteles, chama a atenção para o isomorfismo entre o governo político e o governo doméstico. Nessas duas esferas de governo, busca-se o ideal do autodomínio no complexo terreno dos desejos, de modo a formar uma estrutura de virilidade consigo, mediante uma atividade assimétrica e não-recíproca. Há uma similaridade na relação entre homem e mulher, por um lado, e entre governador e governado, por outro (ORTEGA, 1999, p. 73). Nas palavras de Judith Revel: "O ethos do cuidado de si é, pois, igualmente uma arte de governo dos outros e é por isso que é essencial saber tomar cuidado consigo para bem governar os outros" (REVEL, 2002, p. 60).
} 
abordagem é ressaltar que o bom exercício do governo tem como condição o cuidado de si. Condição fundamental, nesse aspecto, para compreender a passagem do privilégio aristocrático e estatutário de governar à ação política sábia e justa que supõe o conselho filosófico.

É adequado ainda relevar que o fato de Sócrates interessar-se por Alcibíades, somente quando ele perde sua beleza e ambiciona o exercício do governo, indica uma denúncia do déficit pedagógico ateniense. A crítica socrática está enfocada num momento da vida de Alcibíades no qual ele é abandonado pelos pedagogos, justamente quando ele mais precisa ser governado por eles, como convém. Os pretendentes de Alcibíades na sua juventude interessavam-se apenas pela beleza de seu corpo; mas, com o decorrer do tempo, o abandonam, sem o cuidado de governá-lo adequadamente. Pelo contrário, Sócrates está interessado em governar a alma ${ }^{12}$ de Alcibíades, para que ele aprenda a cuidar de si próprio e possa exercitar como convém o governo dos outros. Segue-se que é preciso ocuparse consigo não somente quando se busca governar os outros, mas também quando o governo de si mesmo foi deixado de lado pela educação.

Na análise do Primeiro Alcibíades, são contempladas as questões socráticas fundamentais em torno do exercício do poder político, além do problema da pedagogia e da ignorância que se ignora. A verdade é que Michel Foucault excede a simples leitura do diálogo platônico; dele apropria-se, para enfatizar a importância do cuidado de si como condição fundamental para o governo político dos outros, entre os antigos.

\footnotetext{
${ }^{12}$ O Primeiro Alcibíades versa "sobre a natureza humana". No entanto, quando no diálogo se pergunta pelo eu como objeto do cuidado, inexiste qualquer interrogação sobre a natureza humana. Exige-se o cuidado do eu somente em função dos objetivos do governo sábio e justo: "[...] qual o eu de que devo ocupar-me a fim de poder, como convém, ocuparme com os outros a quem devo governar. É este círculo [que vai] do eu como objeto de cuidado ao saber do governo como governo dos outros que, creio, está no cerne deste final de diálogo" (FOUCAULT, 2001, p. 40). Trata-se de procedimento diferente ao utilizado na República. Nesta, para definir a justiça individual, Platão investiga o que é a justiça na cidade. No Primeiro Alcibíades, para definir o que é o governo justo, interroga-se a alma individual como modelo da cidade. Por isso, a alma (psyché) designa o eu como objeto de cuidado. Platão está distante da concepção de alma prisioneira do corpo, encontrada mais tarde no Fédon, no Fedro ou na República. Que o sujeito seja sua alma significa postulá-lo como "sujeito de ação" (FOUCAULT, 2001, p. 55), que se serve dos órgãos corporais como instrumentos. Numa ampla acepção, servir-se (khrêstai) do eu (heautoû) designa a posição singular ocupada pela alma-sujeito (diferente da almasubstância) em relação com o mundo, com os outros e consigo mesma. Ocupar-se de si significa ser "sujeito de ações, de comportamentos, de relações, de atitudes" (FOUCAULT, 2001, p. 56-57). Tal é a tarefa que deve enfrentar Alcibíades. Sócrates quer mostrar que depende apenas dele o cuidado da alma.
} 
A missão fundamental de Sócrates é convencer Alcibíades de que as ações de governo que ele pretende empreender devem ser antecedidas do controle de suas ambições. É preciso ponderar que isso vale não somente para quem governa, mas também para quem é governado. De um lado, se alguém quiser livremente governar os demais, convém resistir à tentação permanente dos desejos relacionados às ambições políticas; de outro, a melhor maneira de resistir a uma determinada forma de governo está em limitar aquilo que, no indivíduo, parece ser ingovernável, que são os próprios desejos, muitas vezes impetuosos e violentos. De onde o fio condutor da lição socrática: ilusório é pensar ser o direito estatutário suficiente para o bom governo; é imprescindível o conhecimento da arte de governar, do real objetivo da atividade política (que é a distribuição da justiça e o estabelecimento da concórdia, da paz social) e dominar o querer ambicioso pelo exercício da moderação.

Sabemos, pela história, que a administração de Alcibíades em Atenas foi malfadada, em que pese a insistência diligente de Sócrates para que ele governasse adequadamente, a partir do princípio do cuidado de si. A questão que pode ser colocada, portanto, é a da efetividade desse cuidado ético de si em relação à atividade política. Não seria esse tipo de cuidado assaz problemático, para não dizer, inoperante, desde a época de Sócrates?

\section{O Cuidado da Verdade diante do Cuidado Político da Vida}

A fim de analisar essa problemática, podemos nos deslocar para a tetralogia platônica em torno da morte de Sócrates: Eutífron, Defesa de Sócrates, Críton e Fédon. Nos limites deste estudo, será examinado o segundo desses diálogos, A Defesa de Sócrates, no qual Sócrates manifesta uma desconfiança visível em relação à instituição política. A discussão sobre esse diálogo (e o Fédon) ocorre no dia 2 de março de 1983, no curso Le gouvernement de soi et des autres, v. I (2008, p. 286-300) no quadro geral da ética política, e no dia 15 de fevereiro de 1984, no curso intitulado Le courage de la verité: Le gouvernement de soi et des autres, v. II. (2009, p. 67-108), no quadro geral da ética filosófica.

Se, de um lado, Sócrates confiava nas leis que ajudara a elaborar (não propondo, pois, nenhuma pena alternativa ao seu julgamento, possibilidade que lhe era facultada), para ele, o cuidado de si estará vinculado a um estilo de vida alternativo em relação à atividade política institucional. Nesse diálogo, o cuidado de si é sinônimo de cuidado da verdade. Esse será o critério da proposta socrática da inversão de valores na sociedade ateniense (PLATÃO, 1973, 29e-30b). É nuançada a missão divina confiada a Sócrates 
para pôr em prática um cuidado dos atenienses, muito diferente daquele proporcionado pela política institucional.

Na política, cuida-se dos interesses do povo, mas não do próprio povo (PLATÃO, 1973, 36c). Por sua vez, na vida social, cuida-se da fama, da aquisição de riquezas e da ocupação de cargos políticos, prescindindo o cuidado da razão, da verdade e da alma (PLATÃO, 1973, 29d-e). Se o filósofo negligencia fortuna, vantagens cívicas, carreira política ou magistratura, é porque, mediante a escolha de uma maneira de viver singular, procura ser exemplo do cuidado consigo, de modo que os concidadãos cuidem igualmente de si mesmos. A função do filósofo é despertar os concidadãos, o cuidado de si constituindo a tarefa do primeiro despertar.

A vida pautada pelo cuidado de si identifica-se com a prática incessante do exame. Sócrates ressalta que "vida sem exame não é digna de ser vivida" (PLATÃO, 1973, 38a). Como o exame de si é inacabado, somente o cuidado permanente da verdade, da justiça e consigo confere dignidade ao viver, no decorrer da existência. O exame constante mune o filósofo da atitude da coragem. Por meio dela, ele não recua diante do perigo que representa "falar espontaneamente" para o bem dos concidadãos. Permanecem em segundo plano os cálculos referentes às chances de vida $\mathrm{e}$ de morte (PLATÃO, 1973, 28b). O cuidado da verdade é que torna a vida merecedora de sua existência, mesmo que, com isso, ela própria esteja constantemente ameaçada.

Essa relação entre cuidado da verdade e cuidado da vida - que Foucault identificava na filosofia socrática - e sua crítica da política ateniense não deixa de ser a apresentação vertical do próprio modo como Foucault pensava a política institucional, pelo menos a partir do final dos anos $1970 \mathrm{e}$ início dos anos $1980^{13}$, ainda que o contexto e as formas de problematização sejam bem diferentes.

Foucault nota que as políticas socialistas ou (neo)liberais têm o mesmo modus operandi, os mesmos conchavos de sempre. Na política, existe pouca coerência entre aquilo que se diz e aquilo que se pensa, entre aquilo que se pensa e aquilo que se sente, entre aquilo que se sente e aquilo que se vive. Mesmo assim, muitas vezes, os sistemas políticos buscam legitimar seu

\footnotetext{
${ }^{13}$ Creio que essa desconfiança não está relacionada somente com o episódio de apoio, por parte de Foucault, ao Aiatolá Khomeini e que resultou em crítica mordaz a seu posicionamento por boa parte da intelectualidade parisiense. O descrédito de Foucault também tem a ver com a ascensão ao poder do governo socialista francês de François Miterrand, em 1981, e a constatação de que não houvera mudança significativa em relação às práticas políticas dos governos liberais de direita que o antecederam (GROS, F. In: FOUCAULT, 2008, p. 359-360, Nota 39).
} 
governo em nome de uma verdade imposta. Dessa forma, "nada é mais inconsistente que um regime político indiferente à verdade; mas nada é mais perigoso que um sistema político que pretende prescrever a verdade" (FOUCAULT, 1994, p. 687). Ora, nem um nem outro têm um cuidado da verdade.

Provavelmente, o grande desafio do cuidado de si, em face da atividade política, tenha a ver com o cuidado da verdade. Verdade aqui é sinônimo de franqueza, no sentido da coragem de dizer a verdade diante de alguém cujo poder é maior que você ou perante uma maioria que opina contrariamente a você.

Foucault dedicou longos desenvolvimentos sobre essa problemática, quando, desde 1982, mas, sobretudo, nos cursos já citados de 1983 e 1984, passou a entender o cuidado, enquanto cuidado da verdade. Os leitores de Foucault já estão familiarizados com esse conceito, pois ele está diretamente ligado à ideia grega de parrhesia, a qual, por sua vez, se refere à liberdade de palavra, à relação com a verdade por meio da franqueza.

O cuidado da verdade, imprescindível a uma ética do intelectual na sociedade contemporânea, tem muito a ver com a parrhesia. ${ }^{14}$ Principalmente, porque ela designa "uma atividade verbal pela qual um falante exprime sua relação pessoal à verdade e arrisca a própria vida porque reconhece que 'dizer a verdade' é um dever que ajuda outras pessoas (bem como a si próprio) a viver melhor" (FOUCAULT, 1997, p. 9). Dois desdobramentos podem ser enfatizados, a partir dessa designação: o primeiro diz respeito às consequências de "dizer a verdade", o que significa arriscar a própria vida. É o que ocorre quando o filósofo se coloca como tarefa o diagnóstico da realidade, o que significa

14 "La notion de parrhêsia constitue l'objet priviliégé d'étude de Michel Foucault, de 1983 à 1984. [...] On peut définir l'intérêt qu'a suscité chez Foucault ce thème en rappelant d'une part qu'il lui a permis de retraverser le champ de la politique (problème de la structuration des conduites d'autrui: comment gouverner les autres?), après avoir tenté d'isoler et de definir un champ éthique (problème de la structuration du rapport à soi: comment se gouverner soi-même?). D'autre part, il est certain qu'avec ce thème du francparler, du dire-vrai, du courage de la vérité (autant de manières de traduire 'parrhêsia'), Foucault est au plus près de lui-même, au sens où il s'interroge sur le statut de sa propre parole, sur son rôle d'intellectuel public, sur les enjeux de sa fonction. Qu'est-ce qui définitivement fait de Foucault, et pour Foucault lui-même, un peu plus qu'un professeur et un peu moins qu'un militant, un peu plus qu'un érudit et un peu moins qu'un idéologue? Ce fameux 'retour aux Grecs' dont on parle pour le dernier Foucault (celui des années 1980) s'accomplit dans un redéploiement final de la figure de Socrate comme 'parrèsiaste' frère un instant revê, double souriant" (GROS, 2002, p. 155). 
[...] reinterrogar as evidências e os postulados, sacudir os hábitos, as maneiras de fazer e de pensar, dissipar familiaridades admitidas, retomar a medida das regras e das instituições e, a partir dessa reproblematização (na qual ele desempenha seu labor específico de intelectual) participar na formação de uma vontade política (na qual ele tem seu papel de cidadão a realizar). ${ }^{15}$ (FOUCAULT, 1994, p. 676-677).

Mas, ao mesmo tempo em que arrisca a própria vida pelo perigo político que suscita o cuidado da verdade, a vida mesma é que adquire significado. Inversamente e parafraseando Sócrates, uma vida sem cuidado (da verdade) não seria digna de ser vivida.

O segundo desdobramento concerne aos efeitos do cuidado da verdade para a vida de outras pessoas. O dire vrai (o dizer verdadeiro), o cuidado da verdade acarreta o cuidado da vida de outrem. Isso significa, antes de tudo, denunciar a fragilidade à qual a vida tem sido exposta; desconstruir os dispositivos de verdade que se apoiam no discurso do cuidado da vida, mas que, ao mesmo tempo, a tornam insignificante.

Nesse aspecto é que o cuidado filosófico da verdade (desdobramento do cuidado de si) representa um enfrentamento em relação à política, posto que a maioria dos dispositivos de verdade de caráter político, principalmente no decorrer do século XX, estão assentados na gestão e cuidado da vida. Assim, não há, de uma parte, a política, tomada genericamente; e, de outra, a biopolítica, como a relação exclusiva entre política e vida. Salienta Esposito (2004, p. 5):

\begin{abstract}
Nel momento in cui da un lato crollano le distinzioni moderne tra pubblico e privado, Stato e società, locale e globale, e dall' altro si inaridiscono tutte le altre fonti di legittimazione, la vita stessa si accampa al centro di ogni procedura politica: non è ormai concepibile altra política che una política della vita, nel senso oggettivo e soggettivo del termine.
\end{abstract}

Desse modo, como entender o governo político da vida? Para Esposito, ele pode ser referido a um governo da vida ou sobre a vida. Essa diferença está relacionada, por sua vez, à bifurcação lexical dos conceitos de biopolítica

\footnotetext{
${ }^{15}$ Frédéric Gros, ao aludir à realidade da filosofia, problematizada por Foucault, no curso de 1983, esclarece que "encontrar seu 'real' quererá dizer para a filosofia seja fazer atuar, num campo político que, por sua vez, é autônomo, a diferença de sua palavra, de seu discurso [...], seja ainda informar a 'vontade política', quer dizer, propor elementos de estruturação de uma relação consigo específica, de modo a suscitar o engajamento, a adesão e a ação políticas" (GROS, 2008, p. 359).
} 
e biopoder: "[...] intendendo con il primo una politica in nome della vita e con il secondo una vita sottomessa al comando della politica" (ESPOSITO, 2004, p. 5). Quer dizer, a maioria dos dispositivos de verdade das políticas atuais sustenta governar em nome da vida, do seu cuidado e conservação, de sua qualidade e longevidade, no sentido de uma biopolítica; entretanto, tais dispositivos operam igualmente a partir de uma crescente submissão da vida à administração e ao controle de um biopoder.

Essa administração da vida perpassa as sociedades disciplinares e, depois da Segunda Guerra mundial, também as chamadas sociedades de controle. A sociedade disciplinar estava baseada num sistema fechado: confinamento, internamento etc. A maioria dessas instituições de vigilância entra em crise e passa por sucessivas reformas, dando lugar a sistemas mais abertos, suscetíveis de controle. "Por exemplo, na crise do hospital como meio de confinamento, a setorização, os hospitais-dia, o atendimento a domicílio puderam marcar de início novas liberdades, mas também passaram a integrar mecanismos de controle que rivalizam com os mais duros confinamentos" (DELEUZE, 1992, p. 220).

Todavia, o grande paradoxo da época contemporânea é que o dispositivo de verdade do cuidado da vida está acompanhado de práticas que a tornam totalmente dispensável e, no limite, matável. Isso ocorre quando a morte de um grupo biologicamente determinado tem como justificação a própria purificação da vida, como foi o caso do Holocausto do povo hebreu, em nome da pureza da raça ariana (ver AGAMBEN, 2002).

Como sublinha Duarte (2006, p. 103),

[...] é exatamente no momento em que a política assume para si o cuidado e a gestão da vida que o massacre das vidas humanas mais se intensifica, pois o sujeito que pretende assumir o controle dos processos de produção técnica do real é também consumido e aniquilado em massa.

A época contemporânea, na qual a vida parece ter sido objeto de maior cuidado pelo Estado e pela medicina, é paradoxalmente a que mais tem sido acometida por genocídios outrora inimagináveis, ao lançar mão de pretextos racistas e incitação à violência, em razão da xenofobia. O cuidado da vida tem sido correlato da sua manipulação. Não seria esse o "perigo principal" (FOUCAULT, 1994, p. 386), sobre o qual deveria se debruçar a filosofia, na época atual? 


\section{Considerações}

Se houve um deslocamento no pensamento de Foucault, principalmente a partir de 1978, ele não estaria localizado no abandono da política, porém, na problematização do conceito de governamentalidade, porque, ao tornar indissociável o governo político dos outros do governo ético de si mesmo, o pano de fundo da governamentalidade possibilitou entender o cuidado ético de si como inseparável do cuidado político dos outros.

Os últimos trabalhos de Foucault, tais como os Dits et écrits, v. IV (1994), as análises em torno do Primeiro Alcibíades, de Platão, em L'herméneutique du sujet (2001), da parrhesia política, em Le gouvernement de soi et des autres, v. I (2008), e da parrhesia filosófica, em Le courage de la verité: le gouvernement de soi et des autres, v. II (2009), apontam para uma dobra política da ética ou uma "ética como política".

Contudo, se é possível identificar um isomorfismo, nos antigos, entre o cuidado ético de si e o cuidado político dos outros, justamente este último cuidado é apresentado de maneira bem diferente da forma como as instituições políticas "cuidam" dos cidadãos.

Ressalvando todas as diferenças imagináveis, a desconfiança socrática a respeito desse cuidado propalado pela política também está presente no ceticismo de Foucault a respeito da política de seu tempo. Desse modo, quando postulamos que Foucault fez uma revisitação da política a partir da ética, provavelmente ele não estava imaginando outro modelo de política institucional. Pelo contrário, os textos sugerem que pretendia expor o parentesco longínquo entre a constituição contemporânea do intelectual específico que atribui à própria vida uma significação política, mediante atuações e reivindicações pontuais, e a constituição antiga da figura do parrhesiasta, cuja marca era a coragem da verdade.

Para Foucault, essas duas maneiras de constituir-se politicamente como sujeito têm a ver com o cuidado da verdade, algo com o qual as políticas institucionais pouco se importam ou, quando falam da verdade, tentam somente impô-la com o único objetivo de legitimação de seu poder abusivo e excessivo.

Essa busca de legitimação pela verdade é extensiva ao discurso do cuidado da vida, do qual se serve o biopoder, para tornar a vida cada vez mais controlada e administrada. Diante disso, até que ponto o cuidado da verdade - como um dos desdobramentos do cuidado de si - não poderia ser apresentado como uma das instâncias críticas que apontaria a ambiguidade do discurso político em torno da vida? Em que sentido a ética poderia ser problematizada como uma analítica da política? Essas e outras indagações, 
deduzidas dos últimos oito anos de pesquisas efetuadas por Foucault, permitem afirmar que, nesse ínterim, a efervescência de seu pensamento vai muito além de um aparente apaziguamento espiritualizado ou de um silêncio resignado, em razão da recepção crítica de seus trabalhos, desde Histoire de la sexualité, v. I (1976).

CANDIOTTO, César. Ethics and politics in Michel Foucault. Trans/Form/Ação, (Marília); v.33, n.2, p.157-176, 2010

ABSTRACT: The aim of this paper is to analyze how, according to Michel Foucault's ideas, the investigation of the ethics of care of the self might be considered the unfolding of the idea of governmentality, problematized in 1978; we also aim at indicating that this ethics of care of the self is the basis for the political government of others according to the Socratic tradition, and that makes a revisitation of politics possible. However, from Foucault's evaluation of Socrates's view of the Athenian politics until his diagnosis of contemporary politics, this revisitation has been conflicting, at least concerning the way the political institutions care for the citizens. This conflict seems to be paradoxical because, at the same time that biopolitics makes a statement about a politics of life, for it provides its care, preservation, longevity, it is also possible to notice the act of a politics about life, for life is controlled by and subject to biopower. This discrepancy between discourse devices and effective practices reveals an absence of care for truth, understood as the coherence between what is said and what is done. As an unfolding of care of the self, the care for truth might be interpreted as a fundamental reading key for the diagnosis of risks and dangers that recurrently threaten human life.

KEYWORDS: Ethics. Politics. Care of the Self. Care for Truth. Genealogy.

\section{Referências}

AGAMBEN, G. Homo sacer: o poder soberano e a vida nua, I. Belo Horizonte: Ed. UFMG, 2002 (Humanitas; 73).

DELEUZE, G. Post-Scriptum. In: DeLEUZE, G. Conversações. São Paulo: Editora 34, 1992. p. 219-226.

DUARTE, A. Heidegger e Foucault, críticos da modernidade: humanismo, técnica e biopolítica. Trans/form/ação, São Paulo, v. 29, n. 2, p. 94-114, 2006.

EPICURO. Antologia de textos. São Paulo: Abril Cultural, 1973. p. 11-28 (Os pensadores).

ESPOSITO, R. Bíos: biopolitica e filosofia. Torino: Einaudi, 2004.

FOUCAULT, M. Les anormaux. Cours au Collège de France, 1974-1975. Paris: Gallimard/ Seuil, 1999. (Hautes études). 
FOUCAULT, M. L'archéologie du savoir. Paris: Gallimard, 1969 (Bibliothèque des sciences humaines).

Le courage de La vérité: le gouvernement de soi et des autres II. Cours au Collège de France, 1983-1984. Paris: Gallimard: Seuil, 2009.

. Discorso e verità nella Grecia antica. Edizione italiana a cura di Adelina Galeotti. Introduzione di Remo Bodei. Roma: Donzelli, 1997.

Dits et écrits. Paris: Gallimard, 1994. 4 v.

. Du gouvernement des vivants. Cours au Collège de France, Inédito. Disponível em fitas-cassete: C 62 (01-12). Paris: Arquivos IMEC, 1980.

Le gouvernement de soi et des autres. Cours au Collège de France, 1982-1983. Paris: Gallimard/Seuil, 2008.

. L'herméneutique du sujet. Cours au Collège de France, 1981-1982. Paris: Seuil/Gallimard, 2001.

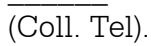

Histoire de la sexualité, I: la volonté de savoir. Paris: Gallimard, 1976.

Histoire de la sexualité, II: L'usage des plaisirs. Paris: Gallimard, 1984.

. Sécurité, territoire, population. Cours au Collège de France, 19771978. Paris: Seuil/Gallimard, 2004.

Subjectivité et vérité. Cours au Collège de France, 1981. Inédito. Disponível em fitas-cassete: C 63 (01-07). Paris: Arquivos IMEC, 1981.

GORDON, C. Governmental rationality: an introduction. In: BURCHELL, Graham; GORDON, Colin; MILLER, Peter. (Org.). The Foucault Effect: Studies in Governmentality. Chicago, IL: University of Chicago Press, 1991. p. 1-48

GROS, F. Situation du cours. In: FOUCAULT, Michel. L'herméneutique du sujet. Édition établie par François Ewald et Alessandro Fontana, par Frédéric Gros, Paris: Seuil/Gallimard, 2001. p. 487-526. (Hautes études).

. La parrhêsia chez Foucault (1982-1984). In: GROS, F. (Org.). Foucault et le courage de la verité. Paris: P.U.F., 2002. p. 155-166.

. À propos de l'Herméneutique du sujet. In: BLANC, Guillaume le; TERREL, Jean. Foucault au Collège de France: un itinéraire. Bordeaux: Presses Universitaires de Bordeaux, 2003. p. 149-163. (Histoire des pensées).

GROS, F. Situation du cours. In: FOUCAULT, M. Le gouvernement de soi et des autres. Cours au Collège de France, 1982-1983. Paris: Gallimard/Seuil, 2008. p. 347-361. 
KERR, D. Beheading the king and enthroning the market: A critique of Foucauldian governmentality. Science \& Society, New York, v. 63, n. 2, p. 173-203, 1999.

LARROSA, J. A libertação da liberdade. In: PORTOCARRERO, V.; CASTELO BRANCO, G. (Org.). Retratos de Foucault. Rio de Janeiro: Nau, 2000. p. 328335.

LEMKE, T. Foucault, governmentality, and critique. Rethinking Marxism, v. 14, n. 3, p. 49-64, Sept. 2002.

MUCHAIL, S. T. Sobre o cuidado de si - surgimento e marginalização filosófica. In: PEREZ, D. O. (Org.). Filósofos e terapeutas em torno da questão da cura. São Paulo: Escuta, 2007. p. 21-32.

ORTEGA, F. Amizade e estética da existência em Foucault. Rio de Janeiro: Graal, 1999.

PLATÃO. A defesa de Sócrates. São Paulo: Abril, 1973 (Os pensadores).

PRADEAU, J.-F. Le sujet ancien d'une politique moderne. Sur la subjectivation et l'éthique anciennes dans les Dits et écrits de Michel Foucault. In: MOREAU, P.-F. Lectures de Michel Foucault. Sur les Dits et écrits, 3. Lyon: ENS Editions, 2003. p. 35-52.

REVEL, J. Le vocabulaire Foucault. Paris: Ellipses, 2002.

SENELLART, M. Les arts de gouverner. Du regimen médiéval au concept de gouvernement. Paris: Seuil, 1995. (Des Travaux)

. La critique de la raison gouvernementale. In: BLANC, Guillaume le; TERREL, Jean (Org.). Foucault au Collège de France: un itinéraire. Bordeaux: Presses Universitaires de Bordeaux, 2003. p. 131-148. (Histoire des pensées).

Situation des cours. In: FOUCAULT, Michel. Sécurité, territoire, population. Cours au Collège de France, 1977-1978. Édition établie par François Ewald et Alessandro Fontana, par Michel Senellart. Paris: Gallimard/ Seuil, 2004. p. 379-411.

(Hautes études).

VEIGA-NETO, A. Coisas do governo... In: RAGO, M.; ORLANDI, L. B.; VEIGA-NETO, A. (Org.). Imagens de Foucault e Deleuze: ressonâncias nietzschianas. Rio de Janeiro: DP\&A, 2002. p. 13-34. 